\title{
Helping EFL Students Avoid Socio-pragmatic Failure: Focus on Nonverbal Intercultural Competence
}

\section{Driss Benattabou ${ }^{1}$}

${ }^{1}$ Moulay Ismail University, Meknes, Morocco, [d.benattabou@umi.ac.ma]

\begin{abstract}
This article examined the vital importance of conjoining between such notions as 'formal culture' and 'deep culture' as two inextricable aspects of EFL teaching and learning. There is a tacit assumption here that if Moroccan learners of EFL are not assisted through recognizing some aspects pertaining to English 'deep culture', many intercultural difficulties and misunderstandings may result. The two aspects of English language learning and teaching should in no way be looked at as being mutually exclusive. Rather, they are two intertwined facets of the same coin. The examination of many instances of intercultural misunderstanding demonstrates that a holistic vision of deep culture (nonverbal behaviour along with some extra-linguistic features of the target language) ought to be incorporated as a basic course supplementing the existing teaching materials geared to foster Moroccan university students' intercultural nonverbal competence. This paper ends up discussing the implications for the implementation of some strategies to foster foreign language students' nonverbal communication skills as an integral part of a broader concept of 'intercultural nonverbal competence'.
\end{abstract}

Keywords: EFL learners; verbal communication; nonverbal cues; deep culture; cultural misunderstanding

\section{Introduction}

This paper sets out to examine the pivotal importance of incorporating the study of EFL nonverbal cues along with its extra-linguistic features to assist foreign language learners to avoid cross-cultural misunderstanding. The first section presents a theoretical background pertaining to the teaching of these nonverbal signs in conjunction with some extra-linguistic features of the target language as essential tools to ensure success in intercultural communication. The second section delineates some instances of potential miscommunication arising from second/foreign language learners' unawareness, both as encoders and decoders, of some extra-linguistic and nonverbal cues. The third section discusses a number of strategies foreign language teachers may exploit to assist students' lack of knowledge of these extra-linguistic features of human face-to-face interaction. The paper ends up illustrating that the incorporation of the target language 'deep culture' course can offer a great deal to the development of intercultural competence among students of EFL in the Moroccan context.

\section{Theoretical Background}

There is a widespread observation among teachers of English as a foreign language that their students are often found to be at a loss when attempting to employ the material taught in the classroom for the expression of a multitude of discoursal functions, particularly when it comes to communication with target language speakers in face-to-face interaction. This is due in part to the 
fact that the structures and the contents of the target language presented and mastered within the classroom context are not enough, and are not easily transferred outside when 'authentic' communication is involved.

Teachers still maintain the simplistic view that their heavy reliance on grammar and syntax is vital and conducive to a good proficiency of the foreign language. However, to avoid any socio-pragmatic failure in any cross-cultural communication, students must be knowledgeable not only of the structural aspects of the target language but also of the conversational formulas regulating speech (Lado, 1972; Hymes, 1972; Ellis, 1986; Smith, 1987; Gumperz, 1990; Kasper \& Blum-Kulka, 1993; Al-Ghamdi, Almansoob, \& Alrefaee, 2019).

Ouakrime (1992), and Sadiqi (1992), among others, have gone even further to argue that communication breakdown could be alleviated if students are exposed not only to 'formal culture'( British/American civilizations, their educational systems, religions, etc.) but also to some aspects of what is coined as 'deep culture', basic components of which are target language beliefs, world views, attitudes, to name but a few (Byram, 1997; Crozet et al., 1999; Gunduz, 2016).

While there is some truth in this, the argument of this paper is that the problem is much more subtle and intricate than this. To foster students' efficiency to communicate appropriately, foreign language teachers must raise students' awareness of both the verbal as well as the non-verbal components of the target language. Although there has been some research to explore the importance of developing learners' intercultural communicative competence at the verbal level (Davies, 1992; Mouaid, 1992; Bentahila, 1992; Bentahila \& Davies, 1997; Benattabou, 2011, Yassin, \& Razak, 2018), little is currently known about its non-verbal level and arguments have often been voiced to note that the issue has not received as much attention as it really deserves (Damnet, 2008).

There is; however, a burgeoning interest in the study of the way the incorporation of the nonverbal intercultural course could assist language learners to avoid the psychological embarrassment they may feel as a direct result of being unable to produce and/or understand certain nonverbal practice s of the target language (Levine and Adelman, 1982; Neu, 1990; Kohonen et al., 2001; Peterson and Coltrane, 2003; Damnet, 2008; Gunduz, 2016).

With this line of reasoning in mind, Damnet (2008) seems to capture the essence of the problem arguing that:

"The acquisition of intercultural nonverbal competence should be considered as an important goal of language learning for English as a language of intercultural and international communication" (Damnet, 2008, p. 66).

There is no doubt that in any social face-to-face interaction communication is transmitted not only through verbal signs as the only main tools to interact and exchange information. Rather, nonverbal ways of communication along with a knowledge of some extra-linguistic features seem to play also a vital role in sending a multitude of meanings.

Anthropologists and sociolinguists have long acknowledged that human interaction takes place through a well-orchestrated combination of verbal and nonverbal systems of communication. Speakers/interactants have long been observed to employ, along with their usage of verbal signs, a wide range of other nonverbal cues, and extralinguistic parameters to express their feelings and emotions. Much of the information we tend to express passes through these two major channels of communication. Eye contact, gestures, and facial expressions, along with other extra-linguistic cues are an essential part of the inter-cultural gamut we tend to rely on. 
My view is that although Moroccan universities have tried to keep abreast with the ever-changing nature of the teaching pendulum, their core remains, unfortunately, the same. There is still an overemphasis on such courses as grammar, syntax, paragraph writing, reading comprehension, spoken English, and oral communication. Although some of these courses purport to equip students with such language functions as greetings, making orders, requests, and apology, they fall short of presenting authentic material and fail to raise students' awareness of the nonverbal cultural discrepancies between the Moroccan culture and those of the English-speaking communities.

More than this, students are usually observed to be linguistically competent, but nonverbally (both as encoders and/or decoders) handicapped. To assist second/foreign language learners use English effectively in intercultural and international interactions, they need to be fully cognizant of some of the conventions and routines underlying the use of nonverbal communication along with some extralinguistic features of what has been referred to as 'deep culture' (Levine \& Adelman, 1982; Kohonen et al., 2001; Peterson \& Coltrane, 2003; Damnet, 2008).

The argument presented in this paper is that the problem of students' failure to come to grips with the proper and appropriate routines governing communication in English is more subtle and multifaceted than this. It is my belief, and without claiming originality for this, that in order to foster students' efficiency in cross-cultural face-to-face interaction, teachers need to increase their students' awareness of both the verbal as well as the non-verbal and extra-linguistic aspects of the target culture. The two sides are but only different facets of the same coin. It is very impossible to embark on the teaching of one divorced from the other, and any attempt to deal with them as being separate from one another would ineluctably be of no avail and may lead to unbalanced results.

Nonverbal communication along with some extralinguistic features germane to the target language have been reported to be another major source of the great mismatch between cultures conducive to crosscultural misunderstandings. Communication problems that may crop up as a result of the learners' unawareness of the cultural differences between their native language/culture and those of the target language/culture are not specific only to the verbal aspects of the language in question, but also to its non-verbal and extralinguistic features. Examples of this relate to such behavioural patterns as private space (proximity), eye contact, nodding, handshaking, hugging, knowledge of the world, beliefs, attitudes, and the like.

Cross-cultural communication barriers are most likely to arise in situations where two interactants (as encoders and/or decoders) do not share the same routines and conventions of nonverbal communication. Damnet (2008) succinctly put it:

\begin{abstract}
"When the speakers involved share the same culture, problems are less likely to arise in this interpretative process. However, experience and research has highlighted how difficulties and miscommunication may inadvertently arise for interactants whose cultures are different from each other" (Damnt, 2008, pp. 1-2).
\end{abstract}

What follows from this is that success in communication does not only hinge on the learners' efficiency in manipulating their messages verbally but also entails an awareness of how to supplement them nonverbally. If nonverbal messages are not compatible with what people expect on the basis of the verbal message then cross-cultural communication problems are very much likely to happen.

One of the premises of this article is that developing intercultural competence requires from foreign language learners not only their ability to produce well-grammatical sentences, but entails at the same time their capability to use and understand a total range of nonverbal and extra-linguistic routines which align with the verbal language that is taking place (Kohonen et al., 2001; Byram, 
2003; Damnet, 2008). Such a view warrants a holistic vision of intercultural competence which encompasses a wide range of linguistic and paralinguistic features characteristic of the target language and culture, including a range of body language practices (e.g., eye contact, proxemics, gestures, facial expressions, etc.) along with some aspects of deep culture (e.g., beliefs, attitudes, world views, attitudes towards time, punctuality, etc.).

\section{Some Areas of Intercultural Misunderstanding}

The existing literature on the teaching of nonverbal signs of communication to foreign language students points towards a host of extra-linguistic cues that, if not properly catered for, may cause a number of cultural misunderstandings. In any human act of communication, interactants (speakers and/or listeners) hinge heavily on their knowledge and understanding of a multitude of dimensions pertaining to a holistic vision of what has been referred to as 'deep culture'.

In this section, we will discuss and delineate some instances of cross-cultural differences regarding the use of both (1) nonverbal cues and (2) some extra-linguistic features that may cause communication breakdown among Moroccan learners of English as a foreign language.

\subsection{Nonverbal signs causing communication breakdown}

What is very intriguing in this respect is that different speech communities may assign different interpretations to the same non-verbal cues. To explain the potential for intercultural misunderstanding between the Moroccan culture and that of the Anglo-American one, let us consider the following examples:

\section{a. Proxemics}

Proxemics, an aspect of nonverbal behaviour, is generally defined as the study of the way people and cultures perceive and use space to achieve interpersonal communication purposes (Hall, 1959; Burgoon et al., 1989, Faulkner, 2005). This term has been referred to as 'physical space' or 'interpersonal distance'. It defines the cultural tolerance for physical contact between interlocutors in any intercultural encounter. Different cultures have diverse perceptions and quite dissimilar attitudes of tolerance towards the notion of one's private space.

In social encounters, particularly in greetings, for instance, most Moroccans do not share the Western view of 'personal space'. The Moroccan convention is that interaction must take place at a much closer distance than that defined by westerners. A full body embrace, for example, among intimate members of the same sex, as displayed by frequent hugging is seen as being culturally more desirable and as 'normal' among Moroccans.

As a matter of fact, in the Moroccan culture, and the Arab world is no exception, people do not mind if they get closer to their addressees. They are far more likely to stand closer to one another while conversing. Such a nonverbal routine is culturally not appreciated if not to say utterly undesirable among members of the Anglo-American community.

In the American culture, for instance, if two interlocutors get too close to one another, they are far more likely to feel being uncomfortable or even threatened because the culturally expected 'comfort zone' has been transgressed. This is perhaps the reason why Americans, and westerners in general, are more expected to use the commonly accepted formulas of 'excuse me', or 'sorry' even for the smallest unintentional body contacts (Levine and Adelman, 1982). 
In short, while such a behavioural pattern of getting too close to one's interlocutor is an 'intimate' gesture among Moroccans and is considered as a sign of intimacy and good friendship, it is culturally resented among westerners and may be seen as an infringement and a transgression of one's privacy.

\section{b. Eye-contact}

Another example relating to students' beliefs and attitudes about what is culturally proper, felicitous, and correct, and what is not is the use of eye-contact. Eye-contact, or looking straight into the other person's eyes for a longer time is considered among westerners as an indication of respect, trustworthiness, and honesty, especially in such interpersonal encounters as between teacher/student, father/son, or employer/employee. The Moroccan speech community; however, often views eye contact in the above situations as an act of defiance and challenge, or as lack of courtesy and respect /?umazal kajfuffija/, literally, 'he keeps staring at me!'.

While avoidance of eye contact is culturally resented among westerners and may be interpreted as a sign of disinterestedness or total carelessness, in the Moroccan context a lowering of the eye is culturally appreciated especially among females /rzina ?uhadra Siniha/, literally 'she is timid and she lowers her eyes'. A female Moroccan student, as a case in point, is socialized to be / rzina /(wise), /he fumija/ 'shy and timid' and /dima sakta/ 'often silent' and therefore has to lower her eyes while talking to foreigners, particularly not of the same sex. This pattern of behaviour is deemed to be an indication of respect and good demeanour.

Conversely, by lowering ones' eyes while talking to a western male teacher, for instance, the female learner would undoubtedly be considered as rude and lacking respect. Among Americans, maintaining eye-contact is an indication that the addressee is listening attentively (Wainwright, 2003; Faulkner, 2005). Female students, therefore, may experience, in this connection, a psychological conflict between the commonly held Moroccan cultural recommendation to lower one's eyes as a sign of appropriate conduct, and the western etiquette to keep eye contact with the addressee irrespective of his/her sex.

\section{c. Touching}

The role of any verbal message is to share feelings and emotions, and nonverbal ways of communication seem to play the same function as well. Touching, as one form of nonverbal practices, can send a number of messages which are different from one culture to another. In the Moroccan culture, it is culturally acceptable in social meetings to shake hands, hold each other's hands for longer times especially among old men, and exchange hugs and kisses.

It is also common practice to kiss someone you greet on both cheeks. These nonverbal routines are signs of intimacy and friendliness. In the Anglo-American culture; however, touches, kisses, and hugs are taken as offensiveness especially among members of the same sex or among strangers because they are meant to transgress one's privacy. While touching and hugging are extremely liked and appreciated by Moroccans to convey expressions of familiarity, they are seen by westerners as offensive and taboo. It is very intriguing to note here also that handshakes among the Japanese are looked at as rudeness; people are more commonly used to bow and lower their bodies as a sign of respect and deference.

\subsection{Extra-linguistic features causing communication breakdown}

Whilst there are quite divergent differences across cultures with respect to the use of nonverbal practices, there are also very significant dissimilarities apparent across a range of extralinguistic features. 


\section{a. Punctuality}

The conventions in the Moroccan culture are that punctuality is not taken very seriously, especially in informal meetings. Tardiness does in no way convey irresponsibility or lack of respect. Coming late; therefore, obviates the need for an apology unless it is conspicuously exaggerated. It is not uncommon among Moroccans to wait up to one hour before a friend may show up without being squeamish about it.

A Moroccan learner's failure to use the appropriate routine formula to express an apology to an English-speaking interlocutor, in this context, may create serious offenses, send unintended messages, or even worse may cause serious 'diplomatic incidents'.

According to the American culture, being punctual shows responsibility and respect for the person you are expected to meet by not keeping him/her waiting for you. Studies (Faulkner, 2005; Damnet, 2008) demonstrate that the Anglo-American community puts a high value on punctuality, and therefore, if you have an appointment, you are culturally expected to come on time, otherwise, you have to apologize.

\section{b. Criticism}

In the English-speaking communities, criticism is looked at as highly instructive because it is meant to draw people's attention to a faulty statement, or an erroneous view that could be remedied and rectified. As a matter of fact, Americans are most of the time stereotyped for being straightforward in their criticism. Directness in issuing negative feedback among Americans may be misinterpreted by Moroccans and may be seen as derogatory and undermining.

Such an attitude is conceived of by Moroccan students as negative and destructive rather than constructive. In most oral presentations, many students in my course of 'Public speaking', for example, do often resent being asked a question or criticized. Any comments that a classmate may raise regarding any issue in the presentation is perceived as undermining and offensive. It is very lamentable that such classroom discussions that have been designed to develop students speaking skills are often overlooked by Moroccan learners as they are seen to be reluctant showing no readiness to express their opinion or challenge the opinions of their classmates.

Accordingly, Moroccan learners of EFL should be warned to make a distinction between a critique and constructive criticism. As opposed to a critique, which is something negative and discouraging, constructive criticism is meant to be negative feedback but with more effective remarks and comments alluding to more improvements and more refined revisions. As with the nonverbal practices delineated earlier, what is considered normal and constructive in one culture may be seen as unusual or very insulting in another.

\section{c. Forms of address}

In intercultural encounters, Americans, save informal contexts or among speakers of uneven social status, have the tendency to address their interlocutors using their first names even if they have just come to know them. Calling a person using his or her first name upon the first meeting is culturally acceptable for American people.

According to the Moroccan etiquette; however, first name calling may conventionally require more time to have recourse to it than has been allowed for among westerners. Such a behavioural tendency would be interpreted as premature and as being "too intimate" (Faulkner, 2005), displaying a fake familiarity and distrustful sociability. 


\section{d. Choice of topic}

A more serious instance would be to conceive of all cultures as being uniform regarding the choice of topics. It would be safer for a foreign language learner to be on his/her guard particularly with respect to taboo topics. Subjects believed to be appropriate, interesting, and customary among members of a cultural community might be seen as disgusting, offensive, or even obscene and perverse among other cultures.

Foreign language learners need, therefore, to be sensitive to how members from diverse cultural backgrounds may react to their choice of the topic for discussion. There are actually personal characteristics that can or cannot be openly inquired about, such as marital status, age, amount of money paid for something, one's income, and many others. Asking a person about his wife/daughter, talking about sexuality, and/or discussing male-female relations are taboo topics for discussion among Moroccans.

Additionally, while asking about a person's income, praising his/her clothes, and/or asking about his/her private life are common practices among Moroccans, these topics are hardly discussed among westerners and must therefore be avoided. Students on both sides must be advised to avoid discussing such culturally sensitive topics to shun any intercultural misunderstanding that may unintentionally arise and cause more embarrassment.

Bentahila and Davies' (1997) study comparing the conversational routines regarding what could be asked about and what could not be among British English and Moroccan Arabic speakers seem to substantiate the same view. It has been argued that Moroccans "when admiring a friend's new acquisition, [they] seem to be free to ask immediately how much it cost, whereas in many cases such a question would not be well received by a British person" (p. 62). In the Anglo-American speech communities, inquiring about a person's age or income are not considered safe topics for discussion.

\section{e. Invitation/offer performance}

One more salient cultural difference between the Moroccan and the Anglo-Saxon conversational styles is in invitation/offer performance. Moroccan invitations/offers tend to be more straightforward, direct, and sometimes, forceful and exhorting. Whereas the British and, to a lesser degree, the Americans have a tendency towards indirectness in their invitations and offers, Moroccans, around a dinner table, for example, tend to urge their invitees to eat more even if they are full and show no sign to eat anymore. Moroccans view forceful invitations as a sign of politeness and hospitality.

In so doing, if we take Leech (1983) as a heuristic framework of interpretation, Moroccans seem to adhere more to the 'Hospitality Principle', as formulated in Leech (1983), and the rule "Be friendly" as posited by Lakoff (1973). In contrast, the British and the Americans would, at the best, opt for indirect invitation strategies, and give options to the invitee to either eat more or stop eating if they feel satisfied. As such, the British and the Americans may be said to adhere more to the "Tact Maxim', as formulated by Leech (1983) and Lakoff's (1973) rule of politeness “Give options". This finding has been empirically evidenced in Talay's (1989) study comparing and contrasting the use of requests and invitations across both Moroccan Arabic and English.

As a matter of fact, though these two cultural groups display different conversational styles in their invitation performance, they adhere to different politeness principles and we may not claim the superiority of one group over the other in terms of politeness. Each group is polite in a different way. However, this contrastive conversational style in invitation performance is likely to cause communication misunderstanding between Moroccan EFL learners and English natives in 
intercultural encounters. The issue at stake, however, is that sometimes a deep-rooted behaviour may surface no matter how much conscious control one may have. One may clearly think about the undesirable impressions the Moroccans would create in their conversational partners if ever they carry over any of their culture-specific behaviour in intercultural encounters, and the unwelcome cross-cultural stereotyping such misunderstanding may cause.

\section{Strategies to Implement in the Classroom}

The aim of this section is to put forward some procedural techniques and teaching strategies for foreign language teachers and curriculum designers to assist their learners to avoid the misfortunes of nonverbal intercultural misunderstandings. A number of instructional techniques have been proposed to serve this purpose, four of which seem to be of more pedagogical significance. The implementation of these techniques in the classroom context is expected to foment EFL learners' consciousness regarding a host of instances of intercultural nonverbal behaviour that may be a source of confusion and misunderstanding among interlocutors of different cultural backgrounds.

\subsection{The Critical Incident Exercise}

First, I start with an example of a 'critical incident exercise' designed by Mouaid (1992) and could be exploited as an insightful technique to draw Moroccan EFL students' attention to the potential threats that a cross-cultural misunderstanding may engender:

"An American tourist found among a group of young Moroccans a guide to take him to the medina in Fes. During the trip, the young Moroccan enthusiastically showed the old monuments to the tourist, patting him on the shoulder to call his attention from time to time, looking at him straight in the eyes during explanations, and walking very close to the tourist even in relatively large streets. Much to the surprise of the Moroccan, after only one hour of the sightseeing, the tourist expressed a wish to go back to the hotel" (p. 35).

This incident describes the problems that might emerge from any cultural misinterpretation of some nonverbal practices used by a Moroccan guide in the company of an American tourist. Because of the Moroccan guide's unawareness of the nonverbal routines characteristic of the American culture, he inadvertently committed three behavioral infringements: (1) by frequently patting on the American shoulder to draw his attention, there is an unintentional breach of the conventions of touching; (2) by staring into the eyes of the American interlocutor for longer periods of time, the Moroccan guide made a violation of the Anglo-American conventions of eye-contact, and (3) by standing closer to the American tourist, there is a further infringement of one's private space.

With an awareness of the cultural norms governing the intercultural nonverbal practices of the Moroccan community, the American tourist would not have quitted the Morrocan guide in that unexpected way. The incident demonstrates how individuals may confuse nonverbal communication practices that are socially alien from their own.

The strength of the critical incident exercise is that it has been reported to be more effective in promoting EFL learners' intercultural competence as it develops their critical thinking and alerts them about the potential areas that may create cross-cultural misunderstanding (Cushner, 1989). Tran et al. (2019) conducted a study comparing two groups of EFL Vietnamese students, one of whom was instructed with one critical incident task per week for a period of ten weeks, and another group receiving Standard English classes. The findings provide further credence in support of the effectiveness of teaching EFL using critical incident tasks. It has also been indicated that the 
implementation of the critical incident technique is a valuable classroom tool for raising awareness of intercultural communication among EFL Vietnamese students.

Peterson and Coltrane (2003) refer to this technique of 'critical incident exercise' as role play during which foreign language learners are encouraged to perform an inappropriate way of greeting either infringing a physical distance or using more handshakes. Their classmates are incited to pin down any form of confusion in that nonverbal act. With the help of the foreign language teacher, students will be assisted to role-play the same incident but with a modified version displaying the culturally accepted formula. The role of the teacher; therefore, is to help students in their identification of the most feasible ways of expressing themselves nonverbally. Teachers may also organize classroom discussions to alert students of the cultural nonverbal routines the two cultural communities may or may not share.

\subsection{Nonverbal communication through visual materials}

Audi-visual devices such as movies and TV fragments may also be exploited in the classroom context to help foster foreign language learners' critical awareness about a wide range of cultural issues specific to the target language and culture. Students will be invited to see in a film, for example, visual materials that embody authentic nonverbal practices akin to those performed by target language interlocutors (Peterson \& Coltrane, 2003).

Additional evidence in support of the importance of using movies in teaching the target language culture along with its nonverbal practices comes from a number of studies (Hurley, 1992; Peterson and Coltrane, 2003; Keene, 2006; Damnet, 2008; Zhang, 2013; Kabooha, 2016).

In addition to their motivational role in language teaching, the exploitation of films is reported to be more effective as it enhances learners' positive attitudes towards the target language and its speech community, improves their awareness of different ways of expressing oneself, and presents authentic input of nonverbal communication displaying a real vision of the target language life-styles.

With the teachers' assistance, EFL learners may watch a film and discuss matters pertaining to paralinguistic features focusing on the use of body language, proxemics, actions, reactions, greetings, farewells, emotions, and attitudes. Without teachers' insightful recognition and grasp of these nonverbal routines specific to the target culture, there is no way for EFL learners to get a conscious understanding of their use and performance. As a matter of fact, EFL teachers should themselves be equipped through in-service training to develop a feel for the nonverbal practices shaping the multicultural classroom.

Fidelman (1997) and Morita (2001), both cited in (Damnet, 2008) have argued for the use of videos and films as supplementary teaching materials to help students learn and see in an explicit way the target language nonverbal communication routines. Damnet (2008) goes further to explain that:

"Films present realistic language in realistic contexts, and also visibly demonstrates meanings of words and expressions as well as portraying some hidden meanings beyond the spoken language, such as body language, facial expressions, and gestures" (Damnet, 2008, p. 69).

Using these digitalized videos and films, and drawing the attention of EFL learners to some nonverbal signals pertaining to the conversational practices of the target community may surely assist them to avoid some of the misconceptions which are the inextricable results of intercultural communication. 


\subsection{Cultural misconception analysis}

Misconception analysis is a type of formative assessment that examines if students, when given nonverbal misconduct, can identify what is the appropriate behavior. This is again another vital strategy my students have often found very intriguing. Aspects of superstition, for instance, which pertain to the Moroccan culture and the corresponding target culture are probed upon and discussed in class. Misconceptions may arise on both sides, and it is the responsibility of the professional practitioner to alert his/her students that superstitions are part and parcel of the cultural heritage of any speech community. The analysis of these cultural items may be more useful to render the classroom atmosphere challenging and educationally more profitable. This cultural comparison could perhaps be applicable to such culture-sensitive aspects as beliefs, attitudes, and stereotypes.

For this purpose, EFL teachers can design classroom activities where they may compare and contrast between a Moroccan Arabic superstitious belief and its equivalent, if any, in the target language/culture. For example, the 'owl' as a word is often misunderstood by Moroccan learners as it carries different cultural meanings. In the English-speaking culture, the owl stands for wisdom and evokes positive overtones. Because of this, the English phrase 'an owlish person' refers to somebody who is wise, decent, and great experienced. In the Moroccan culture, by contrast, the owl invokes in the mind of its native speakers' death and bad omen as the term carries negative meanings. There is a cultural belief among the Moroccan community that if it happens that the owl growls over a house at night, one member of that family may die. Feeling disgusted towards its voice, people in Morocco imbue the word 'owl' with derogatory connotations as it brings most of the time in their view bad news and bad luck.

The task of the language practitioner is to assist foreign language learners to figure out 'the mental images' these culturally-loaded beliefs may evoke across cultures. This knowledge, according to Bryam (1988), would undoubtedly help challenge a wide range of "taken-for-granted" values and assumptions that will make learners in a better position to perceive, understand, and accept that their native language and culture and the target language and culture present two divergent but complementary world views.

\subsection{Cross-cultural comparison and contrast}

Other techniques teachers may employ to assist learners to think critically and become cognizant of such intercultural disparities is through comparison and contrast. Chief among these, perhaps, is to develop a cross-cultural awareness among students regarding such topics as 'time' for example. How do both the Moroccan speech community and that of the English-speaking community look at the concept of time? A cross-cultural comparison of the daily formulas and the proverbial expressions as commonly used by the two speech communities would perhaps serve this purpose (Ciccarelli, 1996; CheeKeong, Yassin, \& Abdulrahma, 2014). I have oftentimes used this technique in such courses as 'Advanced listening and speaking', 'Spoken English' and 'Oral communication', and it has often been perceived as a source of cultural enrichment for my students who consider it funny, enjoyable, and highly instructive.

Kovacs (2017) reports in this connection that the use of proverbs for instructional purposes to compare their contents across cultures may be more insightful for foreign language learners. Such a comparison will raise their awareness about the cultural discrepancies regarding such themes as cultural stereotypes, values, and beliefs. 
As such, students are sensitized and warned against any communication misuse of the target language, and their attention is drawn, for example, to the fact that attitudes towards 'time' may differ tremendously from one speech community to another. For convenience, consider the following proverbial expressions in English:
a. Time is money.
b. Time and tide wait for no man.
c. Procrastination is the thief of time.
d. A stitch in time saves nine.
e. Strike while the iron is hot.
f. Make hay while the sun is shining.
g. Opportunity strikes once.

All these expressions seem to indicate that English-speaking communities care a lot about timing, and people are expected to bang on time, and by implication, tardiness is culturally resented. Time is substantially thought of as crucial and thus must be respected. It is so vital that it has been equated with money. This is perhaps the reason why the big clocks which decorate the majority of the imperial cities in Morocco, like Rabat, Salé, Kenitra, Casablanca, Oujda, to name only a few, were made during the French colonization and may show how much value westerners allocate to time.

In the Moroccan culture; however, there are myriad expressions people may resort to, the majority of which tend to indicate that Moroccans are not as sensitive to the notion of time and punctuality as westerners:

a. /lazerba sla ṣlaћ/ (close to mean: any task needs enough time).

b. /lli zerbu matu/ (close to mean: hastiness leads to death).

c. /lli bya jerbeh lsam țwi:1/ (close to mean: the year is long enough for one to make profits).

d. /blemhel kajtka:1 butenza:1/ (close to mean: hard food (eggplant) should be chewed slowly).

e. /rxaha llah/ (close to mean: relaxation is a guift from God).

f. /lfa:r zzerba:n men sesd lqeț/ (close to mean: a hasty rat is a gift for the cat).

As one may observe from the aforementioned Moroccan sayings, all of them seem to suggest that time is not as important as in western cultures. This implies that the concept of time, and by implication punctuality, is taken lightly by the Moroccan community. This is in complete concordance with Kerouad's (2001) finding comparing American and Moroccan views regarding such questions as 'what is considered a late arrival for an appointment', or 'when having an appointment, how long does one wait for the others to show up?'. The findings of this study demonstrate that the American group turns out to be more sensitive about the notion of tardiness than the Moroccan one.

The Moroccan learners' avoidance of an apology in this context may be seen by the western interlocutor as offensive (Mouaid,1992; Faulkner, 2005). Most Moroccans do not share the western concept of using time, and thus communication breakdown is ineluctably bound to take place as a result of such cross-cultural differences in perceptions regarding the concept of time.

I personally found the cross-cultural comparison of proverbial expressions to be more educationally beneficial for students. What is very intriguing to take note of here; however, is that despite the geographical and cultural distance separating between countries, which may unavoidably make them vary substantially at almost all levels, there are sometimes some aspects they may agree upon and may share in common: 
a. As father as son (English)

b. 'Tel père tel fils' (French)

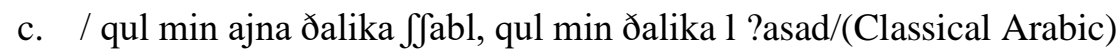

d. / ilwalad jețleS labu:h / (Egyptian Arabic)

e. / iru merwis / (Tamazight).

This knowledge, I believe, is indispensable as it may surely open students' eyes and contribute to the broad-mindedness of their character to see themselves as being on equal footing with other members who belong to widely diverse cultural backgrounds. Such a knowledge may also assist EFL learners dispel any stereotypes and develop a healthy attitude of tolerance and acceptance with those with whom they may happen to disagree with a view to integrate successfully in any multicultural world.

\section{General Discussion and Teaching Implications}

The foregoing discussion seems to suggest that what might seem to be 'normal', 'common sense' and an appropriate formula, be it verbal or non-verbal, to members of the same cultural group might perhaps be seen as offensive and patronizing to people from diverse cultural backgrounds.

As a matter of fact, if the EFL learner takes his/her cultural beliefs and assumptions for granted, then his/her attempts to communicate with westerners will misfire. Coming back to the notion of tardiness, the American/British interlocutor may judge his/her Moroccan addressee as distrustful, careless, and rude, while the Moroccan subject may think of the American/British listener as boastful, unsociable, and too-demanding.

In a like manner, both the British and the Moroccan societies have divergent ways of looking at the appropriate verbal response to belching:

"An English speaker, feeling that to belch is socially offensive, will quickly say pardom me on committing what is perceived as social gaffe; but a Moroccan, viewing it as an indication that he has eaten well, will say with obvious satisfaction /hamdullah/ 'praise to God" (Bentahila nad Davies, 1997, p. 61).

This is indeed a serious barrier that may hinder communication and may plague the success of any social interaction across cultures. If interlocutors from different cultural backgrounds are not warned against these specific particularities' characteristic of both cultures, a wide range of intercultural miscomprehensions are prone to emerge.

The intercultural barriers and conflicts these differences may unwittingly engender could be alleviated if brought by the teacher to the fore and discussed openly. It is also educationally sound for teachers to develop a transcultural awareness of the different attitudes that speech communities endorse regarding beliefs, values, attitudes, stereotypes, what is proper, correct, ethical and what is not in an explicit way with the ultimate objective to help students avoid looking at the target language and culture from their cultural lenses.

The scope of such courses as Translation, Cultural diversity, Cross-cultural studies, and Introduction to culture, for instance, ought to be broadened to incorporate such vital themes as cultural incidents, as described earlier, where role-play dialogues and conversations displaying gross nonverbal communication breakdown are discussed in class. Students would be asked to pin down the source of the misunderstanding and maybe incited with the help of the teacher to suggest different ways to overcome them. 
Students must also be knowledgeable of the widely divergent values and degrees different speech communities may allot to such culturally-loaded topics as family values, time, gender equality, superstition, beliefs, among so many others. Students should be helped to avoid pragmatic failure through an intercultural comparison of the different linguistic and non-linguistic routines used for multiple communicative purposes.

This amounts to saying that students must be knowledgeable of the linguistic and the extralinguistic differences germane to their native language/culture and those of the target language/culture. Such awareness may undoubtedly help instill in the learners a sense of empathy for other speech communities, a sine-qua-non condition, and a vital aspect of Gardner and Lambert's (1972) concept of 'integrativeness', conducive to good language attainments.

After all, the goal of the intercultural communication course is "to help the second language learners develop the ability to use the target language in culturally appropriate ways for the specific purpose of empathizing and interacting with speakers of the target language" (emphasis is mine, Kumaravadivelu, 2008, p.114).

Needless to go into a detailed discussion of the empirical evidence which strongly stresses the correlation between integrative motivation and foreign language learning, because it would not be done justice in the space available. Suffice then to contend that students with favourable attitudes and having developed a sense of empathy, are expected to learn more about the language both in and outside the classroom because they appreciate the target language and its culture, and become satisfied by learning more about it (Spolsky, 1969; Lambert and Gardner, 1972; Gardner, 1982, 1985, 1988; Oxford, 1996; Dornyei, 2003, 2009).

This line of reasoning finds true expression in Ellis's (1986) argument stating that "individuals who are motivated to integrate both the linguistic and non-linguistic outcomes of the learning experience will attain a higher degree of L2 proficiency and more desirable attitudes" ( p. 89).

According to a survey by Ennaji (1996), Moroccan learners of EFL at the university level tend to endorse both an instrumental as well as an integrative orientation towards the learning of English in Morocco. Students are reported to respond positively and to display a favourable appreciation of the different cultural aspects they are presented within the classroom.

If the overwhelming majority of these students ( $82 \%$ ) opted for English studies because of their willingness to keep abreast with the culture and institutions of English speaking communities, and (65\%) among them expressed their belief that English studies will undoubtedly foster intercultural communication with other English speaking countries (Ennaji, 1996, cited in Ennaji, 1996, p.222), and if cross-cultural studies are still invisible or are not allotted a full share in the English syllabi, as is the case with the majority of English departments in Morocco, then this would surely clash with students' motivation and may not respond well to their aspirations, a necessary incentive to excel better in their English studies.

Special care must be made that such an approach to compare the linguistic and extra-linguistic devices across cultures should neither strengthen the learners' ethnocentric tendencies nor threaten or undermine their views of their local values. Increasing students' awareness of such discrepancies as beliefs, stereotypes, cultural conventions/misconceptions would ineluctably make them on their guard to adapt their language and their non-verbal messages accordingly. If language learners are not cognizant and sensitive to such cultural differences between divergent speech communities, they will 
be prone to filter any information through the framework of their cultural background. Through classroom discussion of these cross-cultural components, students will be helped to be culturally sensitive and therefore resist the temptation of any preconceived judgments or misconceptions about other speech communities.

It is my belief that by incorporating such courses as Cultural anthropology, Cross-cultural communication, Cultural awareness, and tolerance, teachers may surely be on the right track to broaden students' knowledge of other English-speaking cultures, and by implication may help increase their chances to succeed. Good proficiency in English, both verbal and nonverbal, and a knowledge of the target culture should find room in the English language teaching programs. The syllabus ought to be flexible enough to be compatible with students' learning needs without overlooking the new requirements of the job market. It follows from this that the objectives of teaching English at the tertiary levels in the Moroccan context should be steadily pruned and up-dated to strike a balance between such tripartite dimensions: What teachers think must be taught, students' needs and preferences, and the ever-changing requirements of the global work environment.

Research has shown that an explicit exposure of students to educational materials geared to instruct nonverbal communication tends to be of more educational gains (Kohonen et al., 2001). Damnet and Borland's (2007) study is very insightful in this connection. Two groups of Thai students learning EFL have been instructed some aspects of nonverbal communication but in a different way. One group was taught about nonverbal communication in an explicit way, while another one was exposed to it in an implicit way through video shows. The results prove very convincingly that it is the first group who displayed a significant grasp of nonverbal communication than the second one. The findings do also lend more credence to the view that nonverbal behaviour is another vital aspect of communication that must be incorporated within the English course syllabus.

Helping students develop a cultural awareness of the target language and culture has been endorsed by a number of authors arguing that target language beliefs, attitudes, and values, along with the target language nonverbal routines must be brought to the fore and discussed in an explicit way (Mcleod, 1976; Kohonen et al., 2001; Damnet, 2008). Others have gone too far to suggest that for successful cross-cultural communication to take place, the learner ought to be culturally well-equipped to become "an ethnographer amateur" (Paulston, 1974; Bryan \& Escarte-sarries, 1991; both cited in Mouaid, 1992).

Teaching foreign languages; therefore, does not only mean teaching the four basic skills, including listening, speaking, reading and writing, and some aspects of what is commonly known as "formal culture" ( British and American civilizations, their history, geography, political institutions, education, etc.), but also some features of what is coined as 'deep culture', basic components of which revolve around such subtle themes as the character of the people, their attitudes, beliefs, values, assumptions, and norms, along with verbal and nonverbal conversational routines, which are inherent and invaluable parameters shaping the behavioural and thinking patterns of the target community (Ouakrime,1992; Sadiqi,1992; Mouaid, 1992; Damnet, 2008).

We are left to agree with Ouakine (1992), Sadiqi (1992), Mouaid (1992), Bentahila and Davies (1997), and Damnet (2008) who endorse a complementary approach to the teaching of English as a foreign language at the university level in which the 'formal culture' of the target language with its 'deep culture' are placed on equal footing. Courses designed with these two aspects in mind may surely impart a substantial bulk of information about the target language and its community that would 
undoubtedly help avoid any cultural misconceptions, biased attitudes, and stereotypical beliefs that may potentially creep in to distort the intended message of any cross-cultural encounter.

What follows from this is that students must be taught such nonverbal issues in order to effectively strengthen the intended message, and more fundamentally perhaps not to transmit unintentional meanings (Kohonen et al., 2001; Peterson and Coltrane, 2003). The corollary of this is that by increasing students' awareness of such key parameters pertaining to cross-cultural communication, both at the verbal as well as the nonverbal sides, we may surely foster their understanding and tolerance of intercultural differences, enhance their appreciation of the target language and culture, and may hopefully render their task of learning enjoyable and educationally conducible to more tangible and profitable benefits.

One way of partly achieving this is through explicit exposure of students of EFL to more input displaying aspects of nonverbal behaviour (Damnet \& Borland, 2007; Damnet, 2008). Students must also be encouraged to develop a feel for the cultural beliefs, assumptions, norms, and values of the target community.

However, a whole host of research questions remain still begging an answer: What non-verbal aspects of the target language should be taught? How many and in what order? When such paralinguistic features pertaining to the target language/culture must be introduced? What procedural techniques EFL teachers may resort to for their instruction? More research avenues concerned with cross-cultural communication on the nonverbal side are still needed. It is towards these questions and possibly other more subtle ones that future research must be geared.

\section{Conclusion}

One may reasonably conclude that foreign language learning is without doubt culture learning. It is true that intercultural difficulties do not result only from the learners' failure to recognize the conversational routines that govern the target language use, but also from their unfamiliarity with the nonverbal paralinguistic features which vary substantially from one culture to another. There are actually stark discrepancies regarding the Moroccan nonverbal behaviour and that of the Englishspeaking communities; yet, there is not much focus on nonverbal behaviour in the Moroccan syllabi, and nonverbal channels of communication, another facet of intercultural communicative competence, remain one of the least researched areas to date.

The foregoing arguments of this paper are perhaps some of the reasons for not maintaining the statusquo in our Moroccan educational settings. There must probably be a need to redefine the objectives of teaching English at the university level. The English language courses may need pruning, refining, and revitalizing to develop a well-balanced mastery of both the verbal as well as the nonverbal features characterizing the learning of the target language. Educationalists must press ahead towards helping students face the truth that interacting via a foreign language is not only interacting while 'looking into the eyes of another' but also while 'looking with the eyes of the other'.

\section{References}

Al-Ghamdi, N., Almansoob, N., \& Alrefaee, Y. (2019). Pragmatic Failure in the Realization of the Speech act of Responding to Compliments among Yemeni EFL Undergraduates. 3L: Language, Linguistics, Literature. 25(4), 227-240. doi:10.17576/31-2019-2504-14. 
Benattabou, D. (2011). Communication studies and the Importance of Developing Cultural Awareness. Maknasat, N 21, Revue de la Faculté des Lettres et Sciences Humaines, Meknes.

Bentahila, A. (1992). "Moroccan Contents, English Medium: A Look at some Moroccan-English Correspondence", In M. Dahbi, N. Tahiri \& T. Miller (Eds.), American studies in North African Universities: An interdisciplinary approach. Rabat. Imprimerie Eljadida.

Bentahila, A. and Davies, A. (1997). "Culture and Language Use: A Problem for Foreign Language Teaching". In Dagmar Scheu Lottgen (ed.). Cultural studies in the classroom: Needs, problems and solutions. Ediciones de la Universidad de Murcia.

Burgoon, J. K., Buller, D. B., \& Woodall, G. W. (1989). Nonverbal communication: The unspoken dialogue. New York Harper \& Row.

Byram, M. (1997). Teaching and Assessing Intercultural Communicative Competence. Clevedon, Multilingual Matters.

Byram, M. (2003). “On being 'bicultural and intercultural"'. In G. Alred, M. Byram, \& M. Flemming (Eds.), Intercultural Experience and Education (pp. 50-66). Clevedon: Multilingual Matters.

CheeKeong, Y., Yassin, A. A., \& Abdulrahma, T. T. A. (2014). Oral communication problems of Yemeni high school EFL students in Malaysia. JApSc, 14(24), 3620-3626.

Ciccarelli, A. (1996). Teaching culture through language: Suggestions for the Italian language class, Italica, 73(4), 563-576.

Crozet, C., Liddicoat, A. J., \& Lo Bianco, J. (1999). Intercultural competence: From language policy to language education. In C. Crozet., A. J. Liddicoat., J. L. Bianco (Eds.), Striving for the third place: Intercultural competence through language education (pp. 1-20). Melbourne, Australia: Language Aus tralia.

Cushner, K. (1989). “Assessing the impact of a culture-general assimilator”. International Journal of Interculturel Relations, 13(2), 125-146.

Damnet, A. (2008). Enhancing Acquisition of Intercultural Nonverbal Competence: Thai English as a Foreign Language Learners and the Use of Contemporary English Language Films. Online published $\mathrm{PhD}$. Thesis. Victoria University Melbourne, Victoria, Australia.

Damnet, A., \& Borland, H. (2007). "Acquiring nonverbal competence in English language contexts: The case of Thai learners of English viewing American and Australian films". Journal of Asian Pacific Communication, 17(1), 127-148.

Davies, E. (1992). "Routines and Realities: Some Sources of Misunderstanding in Cross-cultural Communication", In M. Dahbi, N. Tahiri \& T. Miller (Eds.), American studies in North African Universities: An interdisciplinary approach. Rabat. Imprimerie Eljadida.

Dornyei, Z. (2003). Attitudes, orientations, and motivations in language learning. Malden Mass: Blackwell Publishing.

Dornyei, Z. (2009). Motivation in Second and Foreign Language Learning. Language Teaching, 3, $117-135$.

Ellis, R. (1986). Understanding second language acquisition. Oxford, OUP. 
Ennaji, M. (1996). "An Evaluative Survey of the English Syllabus at the University: Is there an Alternative?" in Dahbi, M; Ezroura, M, \& Haddad,T (eds.) (1996) Cultural Studies, Interdisciplinary, and the University. Conferences and Colloquia, $\mathrm{N}^{\circ} 60$. Publications of the Faculty of Letters and Human Sciences- Rabat.

Faulkner, H. (2005). An Introduction to American Culture: Contradiction and Compromise. Studies and Research series Nr.13. Moulay Ismail University, School of Arts and Humanities, Meknes.

Gardner, R. C. (1982). Language attitudes and language learning. Attitudes towards language variation, 132-147.

Gardner, R. C. (1985). Social psychology and second language learning: The role of attitudes and motivation. London: Edward Arnold.

Gardner, R. C. (1988). The socio-educational model of second-language learning: Assumptions, findings, and issues. Language learning, 38(1), 101-126.

Gardner, R. C., \& Lambert, W. E. (1972). Attitudes and motivation in Second-language learning. Boston, MA: Newbury House Publisher.

Gumperz, J. (1990). "The conversational analysis of interethnic communication". In : R.Scarcella, E.S. Andersen et S.D. Krashen (eds.), Developing Communicative Competence in a Second language. Boston, Heinle \& Heinle Publishers, p.223-238.

Gündüz, N. (2016). Sociopragmatic elements and possible failure in EFL teaching. Dil Dergisi, 1(167), 49-65.

Hall, E. T. (1959). The Silent Language. Newyork: Doubleday \& Company, Inc.

Hurley, D. S. (1992). Issues in teaching pragmatics, prosody, and non-verbal communication. Applied Linguistics, 13(3), 259-280.

Hymes, D. (1972). "On Communicative Competence". In PRIDE, J. B. \& HOLMES, J. (Eds.) Sociolinguistics. Harmondsworth, UK, Penguin Books.

Kabooha, R. H. (2016). "Using Movies in EFL Classrooms: A Study Conducted at the English Language Institute (ELI), King Abdul-Aziz University". English Language Teaching, 9(3).

Kasper, G., \& Blum-Kulka, S. (Eds.). (1993). Interlanguage Pragmatics. Oxford: Oxford University Press.

Keene, M. D. (2006). "Viewing video and DVD in the EFL classroom". Bunkyo Gakuin University Journal, 8(1), 217-234.

Kerouad, S. (2001). An Evaluation of cultural competence and its development among Moroccan learners of English at the university. Unpublished doctoral dissertation. Faculty of Dhar Lmahraz. Fes.

Kohonen, V., Jaatinen, R., Kaikkonen, P., \& Lehtovaara, J. (2001). Experiential learning in Foreign language Education. Malaysia: Longman.

Kovacs, G. (2017). "Culture in Language Teaching. A Course Design for Teacher Trainees". Acta Univ. Sapientae. Philologica, 9, 3, (2017) 73-86.

Kumaravadivelu, B. (2008). Cultural Globalization and Language Education. New Haven, CT: Yale University Press. Lin, A. (Ed.). 
Lado, R. (1972). Teaching English as a Second Language: Patterns of Difficulty in Vocabulary. New York: McGraw-hill Companies Inc.

Lakoff, R. (1973). The logic of politeness: Or, minding your p's and q's. In C. Corum, T. Cedric SmithStark, \& A. Weiser (Eds.), Papers from the 9th Regional Meeting of the Chicago Linguistic Society. Chicago Linguistic Society, 292-305.

Leech, G. (1983). Principles of pragmatics. London: Longman.

Levine, D. R., \& Adelman, M. B. (1982). Beyond language: Intercultural Communication Competence for English as a Second Language. Prentice-Hall.

McLeod, B. (1976). "The Relevance of Anthropology to Language Teaching". TESOL Quarterly 10(2): 211-20.

Mouaid, F. (1992). "Two Techniques foe Teaching Time and Distance in American Culture", in Dahbi,M, Tahri,N and Miller,T (eds.) (1992) American Studies in North African Universities. An Interdisciplinary Approach. Rabat. Imprimerie Eljadida.

Neu, J. (1990). "Assessing the role of nonverbal communication in the acquisition of communicative competence in L2". In Scarcella, R., Andersen E. S., and Krashen S. D. (Eds.), Developing communicative competence in a second language (pp. 121-138). New York, NY: Newbury House Publishers.

Ouakrime, M. (1992). “Formal' and 'Deep' Culture for EFL students: Focus on the Learner". In Dahbi, M., Tahiri, N. and Miller, T. (Eds.), American Studies in North African Universities. An Interdisciplinary Approach. Rabat. Imprimerie Eljadida.

Oxford, R. L. (1996). "New pathways of language learning motivation". In Oxford, R. L. (Ed.) Language Learning Motivation: Pathways to the New Century. (pp. 1-8) Honolulu, HA: University of Hawaii Press.

Peterson, E. \& Coltrane, B. (2003). "Culture in Second Language Teaching, Center for Applied Linguistics". www.cal.org/resources/Digest/digest pdfs/0309peterson.pdf, [Date of Access: 10.05.2020]

Sadiqi, F. (1992). "A cross-cultural approach to the teaching and learning of English in Moroccan universities". A. In M. Dahbi, N. Tahiri \& T. Miller (Eds.), American Studies in North African Universities: An Interdisciplinary Approach. Rabat. Imprimerie Eljadida.

Smith, L. E. (1987). Discourse across Cultures: Strategies in World Englishes. New York, Prentice Hall.

Spolsky, B. (1969). “Attitudinal Aspects of Second Language Learning”. Language Learning, 19, 271283.

Talay, M. (1989). Contrastive Speech Act Strategies: A Case Study of Requests and Invitations in Moroccan Arabic and English. Unpublished D.E.S dissertation. Sidi Mohammed Ibn Abdellah University, Fes. Morocco.

Tran T. Q. T., Admiraal W. \& Saab N. (2019). "Effects of critical incident tasks on the intercultural competence of English non-majors". Intercultural Education, 30(6), 618-633.

Wainwright, G. R. (2003). Teach yourself body language. London: Hodder Headline Ltd. 
Yassin, A. A., \& Razak, N. A. (2018). Request Strategies: A Contrastive Study Between Yemeni EFL and Malay ESL Secondary School Students in Malaysia. Asian Social Science, 14(12).

Zhang, Q. (2013). The impact of film and film-based activities on the attitudes of English speaking secondary-school students toward L2 Chinese. Creative Practices in Language Learning and Teaching (CPLT), 1(2), 1-17. 